\title{
Mycobacterium cosmeticum sp. nov., a novel rapidly growing species isolated from a cosmetic infection and from a nail salon
}

\author{
Robert C. Cooksey, ${ }^{1}$ Jacobus H. de Waard, ${ }^{2}$ Mitchell A. Yakrus, ${ }^{1}$ \\ Ismar Rivera, ${ }^{2}$ Marina Chopite, ${ }^{2}$ Sean R. Toney, ${ }^{1}$ Glenn P. Morlock ${ }^{1}$ \\ and W. Ray Butler ${ }^{1}$
}

Correspondence

Robert C. Cooksey rcooksey@cdc.gov
Non-tuberculous mycobacteria (NTM) were first reported in pathological human secretions in 1884 (Bloom, 1885),

Published online ahead of print on 9 July 2004 as DOI 10.1099/ ijs.0.63238-0.

Abbreviations: NTM, non-tuberculous mycobacteria; PRA, PCR restriction analysis; RAPD, random amplified polymorphic DNA; RGM, rapidly growing Mycobacterium.

The GenBank/EMBL/DDBJ accession numbers for the $16 \mathrm{~S}$ rRNA and hsp65 gene sequences of strain LTA-388 ${ }^{\top}$ and the 16S rRNA and hsp65 gene sequences of strain 2003-11-06 are AY449728AY449731, respectively.

A micrograph showing acid-fast bacilli, a photograph showing colonies of strain LTA-388 ${ }^{\top}$ and photographs showing hsp65 PRA patterns and PFGE and RAPD typing patterns are available as supplementary material in IJSEM Online. only 2 years after Koch reported the tubercle bacillus. Prior to the early 1980s, reports of diseases caused by NTM were somewhat sporadic and the diseases were often associated with environmental sources (Falkingham, 1996). Skin and wound infections following invasive procedures are relatively rare ( $\leqslant 5 \%$ of procedures) and NTM are involved only occasionally (Murillo et al., 2000). The most common NTM species associated with primary cosmetic infections are rapidly growing Mycobacterium (RGM) species including Mycobacterium chelonae, Mycobacterium abscessus and Mycobacterium fortuitum. The NTM also appear to be gaining importance as opportunistic pathogens, particularly among immunocompromised patients in developed nations (Falkingham, 1996).

In a recent study involving a nail salon in Atlanta, GA, USA, 
two cases of furunculosis caused by Mycobacterium mageritense were identified. Three additional NTM isolates from cultures obtained from footbaths and a sink drain were identified as 'Mycobacterium goodii/Mycobacterium smegmatis' on the basis of mycolic acid patterns, determined by HPLC, showing features of both species (Gira et al., 2004). A similar pattern was also observed for an isolate from a culture of a granulomatous subdermal lesion of a female patient in Venezuela who was undergoing mesotherapy with an unknown substance(s) for a cosmetic purpose (weight loss). We evaluated these isolates by using a polyphasic approach that included microscopic and macroscopic morphological examination, biochemical and antimicrobial drug-susceptibility patterns, nucleotide sequence analyses of three taxonomically useful regions of the $r p o B$, $h s p 65$ and $16 \mathrm{~S}$ rRNA genes and strain typing by random amplified polymorphic DNA (RAPD) electrophoresis and PFGE of large restriction fragments. Our data indicate that the four isolates previously identified as ' $M$. goodii/M. smegmatis' were, in fact, representative of two strains of a novel RGM species.

The isolate taken from a patient was obtained by treating material from the granulomatous lesion with $\mathrm{N}$-acetylL-cysteine $(0 \cdot 1875 \%, \mathrm{w} / \mathrm{v})$ and $\mathrm{NaOH}(1 \%, \mathrm{w} / \mathrm{v})$ and inoculating Löwenstein-Jensen (LJ) medium as previously described (Kent \& Kubica, 1985). The environmental isolates were obtained from swabs of sink and footbath drains, which were placed in $2 \mathrm{ml}$ Middlebrook \& Cohn 7H9 broth (Remel) and decontaminated with $0.005 \%$ $(\mathrm{w} / \mathrm{v})$ cetylpyridinium chloride. An aliquot $(1 \mathrm{ml})$ of each broth specimen was filtered through $0 \cdot 45-\mu \mathrm{m}$ filters that were washed twice with $100 \mathrm{ml} 0 \cdot 00425 \%(\mathrm{w} / \mathrm{v})$ monopotassium phosphate buffer, and incubated on Middlebrook 7H10 agar (Remel) plates containing oleic acid albumin dextrose complex enrichment at $35^{\circ} \mathrm{C}$. Mycolic acids derivatized as $p$-bromophenacyl esters were examined by using a standard UV-HPLC method (Butler et al., 1996) and a model System Gold HPLC system (Beckman Coulter) equipped with a Beckman C18 reverse-phase ultrasphereXL cartridge and a Beckman model 166 UV detector. Control strains for HPLC included M. smegmatis ATCC $19420^{\mathrm{T}}$, M. mageritense ATCC $700351^{\mathrm{T}}$, Mycobacterium wolinskyi ATCC $700010^{\mathrm{T}}$ and M. goodii ATCC $700504^{\mathrm{T}}$.

Antimicrobial drug-susceptibility testing was performed in cation-supplemented Mueller-Hinton broth by using a microdilution method, and interpretations of MICs were made according to NCCLS standards for organisms that grow aerobically (NCCLS, 2002). Microscopic analysis of acid-fast bacilli following Kenyoun staining, and testing for colonial morphology, pigment production, single-source carbon utilization, growth rate, tolerance of elevated incubation temperature $\left(45^{\circ} \mathrm{C}\right)$ or $5 \%(\mathrm{w} / \mathrm{v}) \mathrm{NaCl}$, iron uptake, niacin production, nitrate reduction, arylsulfatase production and ability to grow on MacConkey agar without crystal violet were performed as previously described (Kent \& Kubica, 1985). Media and reagents for biochemical tests were prepared at the Centers for Disease Control and Prevention (CDC), with the exception of niacin test strips and nitrate-reduction broth and reagents, which were obtained from Remel. The results of biochemical tests were read after 7 and 14 days incubation at $28^{\circ} \mathrm{C}$, except for arylsulfatase, which was read after 3 and 14 days incubation, and ability to grow on MacConkey agar without crystal violet, which was read after 5 and 11 days, as described in a standard protocol for biochemical testing of mycobacteria (Kent \& Kubica, 1985). Control strains for biochemical testing included M. smegmatis ATCC 35797, M. fortuitum ATCC $6841^{\mathrm{T}}$, M. chelonae ATCC $35752^{\mathrm{T}}$, Mycobacterium avium ATCC 35713 and a BCG strain of Mycobacterium bovis (ATCC 35731), all of which were from the stock collection of the Mycobacteriology Branch of the CDC.

Genotypic tests were performed using DNA extracted from bacteria grown in complete Middlebrook \& Cohn 7H9 broth (Remel) with a modified bead-agitation method as previously described (Cooksey et al., 2003). Oligonucleotide primers for PCR restriction analysis (PRA) of the $h s p 65$ gene and for sequencing of regions of the $r p o B, h s p 65$ and $16 \mathrm{~S}$ rRNA genes are shown in Table 1. Amplification of these regions by PCR was performed in $200 \mu \mathrm{l}$, thin-walled, flat-top PCR tubes using $25 \mu$ l HotStar Taq polymerase master mix (Qiagen), $100 \mathrm{nM}$ primers, $1 \mu \mathrm{DMSO}$ and $1 \mu \mathrm{l}$ template in a final volume of $50 \mu \mathrm{l}$. The PRA was performed using a $441 \mathrm{bp}$ fragment of the $h s p 65$ gene, which was amplified using primers TB11 and TB12 (Telenti et al., 1993). Conditions for PCR thermocycling, restriction with BstEII and HaeIII and electrophoresis were as previously described (Hernandez et al., 1999; Cooksey et al., 2003). Control strains for hsp65 PRA included Mycobacterium hodleri DSM $44183^{\mathrm{T}}$, Mycobacterium frederiksbergense NRRL B-24126, Mycobacterium neoaurum ATCC 25796, Mycobacterium diernhoferi ATCC $19340^{\mathrm{T}}$, M. smegmatis ATCC $19420^{\mathrm{T}}$, M. mageritense ATCC $700351^{\mathrm{T}}$, M. wolinskyi ATCC $700010^{\mathrm{T}}$ and M. goodii ATCC $700504^{\mathrm{T}}$. Sequence analysis of the $441 \mathrm{bp}$ region of the $h s p 65$ gene was performed using a $600 \mathrm{bp}$ template obtained under the same PCR conditions as for PRA, except that primers HSPF1 and HSPR1 (Table 1) were used for amplification and for sequence analyses of sense and antisense DNA strands. A $360 \mathrm{bp}$ region of the $r p o B$ gene that was shown to be polymorphic among 26 Mycobacterium species was amplified under conditions that were similar to those used for the $h s p 65$ gene amplification, except that the annealing temperature was $58^{\circ} \mathrm{C}$ and primers RPO5' and RPO3' (Lee et al., 2003) were used for amplification and sequencing reactions. A region of the $16 \mathrm{~S} \mathrm{rRNA}$ gene from nucleotide 8 to 1542 (Escherichia coli numbering) was amplified using primers $\mathrm{pA}$ and $\mathrm{pH}$, as described previously (Edwards et al., 1989; Floyd et al., 1996), and sequenced by using three forward and three reverse primers (Table 1).

Amplicons that were used as templates for sequence analyses were purified by using QiaQuick columns (Qiagen) and diluted 10 -fold in type 1 water. Sequencing reactions 
Table 1. Oligonucleotide primers used in genotypic characterization of strains

\begin{tabular}{|c|c|c|c|c|c|c|}
\hline Gene & Accession no. & Primers & Reference(s) or sequence & Nucleotides & Product (bp) & Assay \\
\hline rpoB & P47766 & $\mathrm{RPO}^{\prime} / \mathrm{RPO}^{\prime *}$ & Lee et al. (2003) & $902-1261$ & 360 & Sequence \\
\hline hsp65 & M15467 & $\mathrm{TB} 11 / \mathrm{TB} 12^{*}$ & Shinnick (1987); Telenti et al. (1993) & $396-836$ & 441 & PRA \\
\hline 16S rRNA & X15916 & $\mathrm{pA} / \mathrm{pH}^{*}$ & Edwards et al. (1989) & $8-1542$ & 1535 & Sequence \\
\hline 16S rRNA & J01859 & AIF & ctggctcaggacgaacgctg & $20-39$ & None & Sequence \\
\hline $16 \mathrm{~S}$ rRNA & J01859 & $54 \mathrm{R} \dagger$ & tctagtctgcccgtatcgccc & $654-634$ & None & Sequence \\
\hline 16S rRNA & J01859 & $16 \mathrm{R} \dagger$ & ataaggggcatgatgacttgac & $1213-1192$ & None & Sequence \\
\hline $16 \mathrm{~S}$ rRNA & J01859 & $\mathrm{H} 1 \mathrm{R} \dagger$ & ccagccgcaccttccggtac & $1530-1511$ & None & Sequence \\
\hline
\end{tabular}

${ }^{\star}$ Forward/reverse complement sequence.

$\dagger$ Reverse complement sequence.

contained $2 \cdot 5 \mu$ diluted amplicon, $8 \mu$ master mix from the Dye Terminator Cycle Sequencing with Quick Start kit (Beckman Coulter), 2.0 $\mu \mathrm{l} 1 \cdot 6 \mu \mathrm{M}$ primer and $7 \cdot 5 \mu \mathrm{l}$ type 1 water. Cycle sequencing was performed by using a GeneAmp model 9700 thermocycler (PE Applied Biosystems) according to directions in the Dye Terminator Cycle Sequencing with Quick Start kit. Sequencing products were purified and dried using a Pellet Paint NF coprecipitant kit (Novagen), according to the manufacturer's instructions, resuspended in $40 \mu \mathrm{l}$ sample loading buffer and then sequenced using a model CEQ 8000 fluorescence capillary sequencer (Beckman Coulter). The SEQUENCHER version 4.0 software (Gene Codes) was used for assembly of the $16 \mathrm{~S}$ rRNA gene sequence. The sequence was compared with sequences deposited in public databases including GenBank (National Center for Biotechnology Information at http://www.ncbi.nlm.nih.gov/), by using the standard BLAST program (BLASTN; NCBI/NLM/NIH), and with the peer-reviewed database at Ribosomal Differentiation of Medical Micro-organisms (RIDOM) at http://www.ridomrdna.de/ (Harmsen et al., 1999). The species with the most similarity to the $16 \mathrm{~S}$ rRNA gene query sequences were selected for phylogenetic analysis. Similarity comparison, multiple sequence alignments and phylogenetic analyses of $16 \mathrm{~S}$ rRNA gene sequences with pre-compiled aligned RNA sequence data at the RDP-II at Michigan State University (East Lansing, MI, USA) at http://rdp.cme. msu.edu/index.jsp (Cole et al., 2003), were performed by using online phylogenetic programs in PHYLIP version $3.5 \mathrm{c}$ (Felsenstein, 1989) at the PHYLIP interface at this web site. RGM species with similar 16S rRNA gene sequences were downloaded from RDP-II for analysis, and a 16S rRNA gene sequence from Mycobacterium tuberculosis was selected as the evolutionary outgroup. A distance matrix was determined with the DNADIST program (Felsenstein, 1989); a phylogenetic relationship inferred with the parameter defined by Jukes \& Cantor (1969), an unambiguous alignment mask, was automatically applied and a tree was constructed using the neighbour-joining method (Saitou \& Nei, 1987).

The DNA preparations used for PCRs were also utilized for typing the isolates, using RAPD electrophoresis as described previously (Cooksey et al., 2003). The oligonucleotide primer used for RAPD typing was IS986-FP (5'-ACGCTCAACGCCAGAGACCA) (Linton et al., 1994). Typing of isolates by using PFGE of large restriction fragments ( $>48 \mathrm{kbp}$ ) was performed as previously described (Hector et al., 1992), except that DNA samples were restricted with $40 \mathrm{U}$ AseI (Invitrogen). Samples underwent electrophoresis in $1 \%(\mathrm{w} / \mathrm{v})$ agarose that was prepared and run in $0.5 \times \mathrm{TBE}$ buffer $(0.445 \mathrm{M}$ Tris/borate, $0.01 \mathrm{M}$ EDTA, pH 8.3) using a contour-clamped homogeneous electric field electrophoresis/direct repeat (CHEF-DR) pulse electrophoresis system (Bio-Rad) set for 5-20 s ramping at $200 \mathrm{~V}$. Thiourea was added to the running buffer (final concentration, $50 \mathrm{mM}$ ) to prevent DNA degradation during electrophoresis (Romling \& Tummler, 2000).

Microscopic examination of acid-fast bacilli smears revealed that isolates LTA-388 ${ }^{\mathrm{T}}$ and 2003-11-06 were acid-fast, with no chains and few clumps of bacteria. The dimensions of a typical bacillus were approximately $0.55 \times 1.5 \mu \mathrm{m}$ by comparison with a microscopic micrometer (Carl Zeiss). Colonies that appeared on Middlebrook 7H10 agar plates or LJ agar slants after aerobic incubation for 3 days at either 28 or $37^{\circ} \mathrm{C}$ were smooth, dome-shaped, opaque and possessed a pale-yellow pigment. A micrograph showing acid-fast bacilli and a photograph showing colonies of strain LTA- $388^{\mathrm{T}}$ are available as Supplementary Figs A and $\mathrm{B}$ in IJSEM Online. The isolates grew on MacConkey agar without crystal violet but not on LJ agar containing $5 \%$ $(\mathrm{w} / \mathrm{v}) \mathrm{NaCl}$ or in Middlebrook $7 \mathrm{H} 9$ broth at $45^{\circ} \mathrm{C}$.

Biochemical testing showed that the four isolates were positive for iron uptake, nitrate reduction, 14-day arylsulfatase production and for utilization of D-mannitol, 
D-xylose, iso-myo-inositol, L-arabinose, D-trehalose and citrate. They were negative for D-sorbitol utilization and for production of niacin and 3-day arylsulfatase.

Mycolic acid patterns determined by using HPLC were identical for the three isolates from the nail salon in the USA, and this pattern was closely similar to that of the isolate of the female patient in Venezuela. The closely similar patterns of the two strains were substantially different from the patterns of other RGM species, but they most closely resembled reference mycolic acid patterns of $M$. smegmatis, M. goodii, M. wolinskyi and M. mageritense. The type strains of these four species were analysed concurrently with strains LTA-388 ${ }^{\mathrm{T}}$ and 2003-11-06 (Fig. 1). The most notable similarities in the mycolic acid patterns resided with the study strains. Visual comparison of mycolic acid patterns for the other species revealed major differences in the number of peaks and in peak heights, criteria that are used to distinguish mycobacterial species (Butler \& Guthertz, 2001).

The isolates also had a unique hsp65 PRA pattern in comparison with those of species included in the $M$. smegmatis group and other species included in a multicentre web site for hsp65 PRA patterns at http://app.chuv.ch/ prasite/index.html. A photograph showing the patterns obtained after digestion of the $441 \mathrm{bp} h s p 65$-PCR product with BstEII or HaeIII for the four isolates along with those for M. goodii, M. wolinskyi and M. smegmatis is available as Supplementary Fig. C in IJSEM Online. Fragment sizes were determined subsequently by DNA sequence analysis for the four isolates: these were found to be 310 and $130 \mathrm{bp}$ for BstEII and 140, 96, 80, 40, 36, 32 and 16 bp for HaeIII.

Strain-typing patterns produced by RAPD electrophoresis after amplification using primer IS986-FP and by PFGE after digestion of DNA with AseI matched for isolates 2003-11-06, -24 and -30. The RAPD pattern for these isolates consisted of two prominent bands representing approximately 450 and $320 \mathrm{bp}$. The RAPD pattern for isolate LTA- $388^{\mathrm{T}}$ consisted of multiple bands; the most prominent bands represented approximately 500 and $600 \mathrm{bp}$. The PFGE pattern for this isolate consisted of six prominent bands between 97 and $242 \mathrm{kbp}$; only two of these bands were approximately equal in size to any of the eight prominent bands in this size range for the environmental isolates. Therefore, the three isolates obtained from environmental sources at the nail salon were considered to represent one strain, and isolate LTA- $388^{\mathrm{T}}$ represented another strain. Photographs of PFGE and RAPD typing patterns are available as Supplementary Fig. D in IJSEM Online.

According to NCCLS interpretive standards, each of the four isolates was susceptible to the eight antimicrobial drugs that were tested. The MICs for the drugs were the same for each of the three isolates from the nail salon: ciprofloxacin, $0.25 \mu \mathrm{g} \mathrm{ml}^{-1}$; amikacin, $4 \mu \mathrm{g} \mathrm{ml}^{-1}$; imipenem, $\leqslant 1 \mu \mathrm{g} \mathrm{ml}^{-1}$; tobramycin, $4 \mu \mathrm{g} \mathrm{ml}^{-1}$; clarithromycin, $0.25 \mu \mathrm{g} \mathrm{ml}^{-1}$; sulfamethoxazole, $8 \mu \mathrm{g} \mathrm{ml}^{-1}$; doxycycline, $\leqslant 0 \cdot 25 \mu \mathrm{g} \mathrm{ml}^{-1}$; and cefoxitin, $8 \mu \mathrm{g} \mathrm{ml}^{-1}$. These MICs were also observed for the isolate from the patient in Venezuela, except that the MIC for sulfamethoxazole was $32 \mu \mathrm{g} \mathrm{ml}^{-1}$.

Sequences of portions of the $r p o B$ (321 bp), hsp65 (441 bp) and 16S rRNA (1506 bp) genes were identical for isolates LTA-388 ${ }^{\mathrm{T}}$ and 2003-11-06. The GenBank database was interrogated using a $189 \mathrm{nt}$ sub-sequence of the $r p o B$ gene sequence that corresponded to the $216 \mathrm{nt}$ hypervariable region previously used in a multi-alignment analysis of 26 Mycobacterium species (Lee et al., 2003). We found that our sequence was unique and that the most closely related sequences were from $M$. fortuitum and $M$. mageritense (identity score, $88 \%$ ). A search of the GenBank database for similarity to the $441 \mathrm{bp} h s p 65$ sequence revealed that

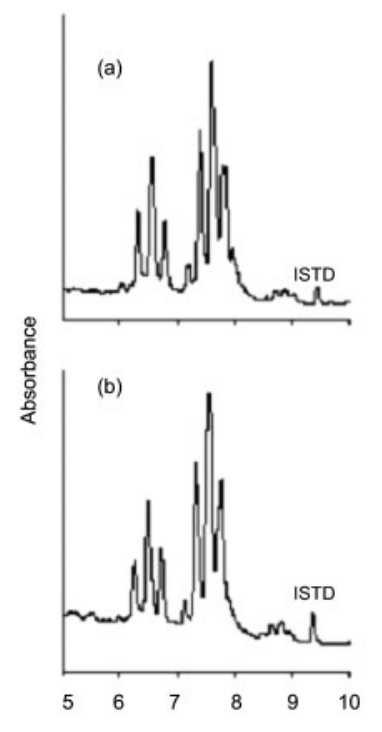

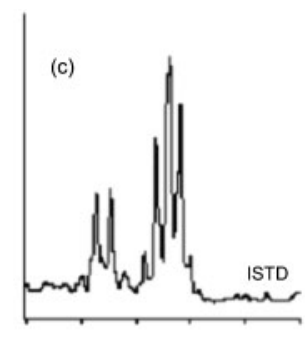

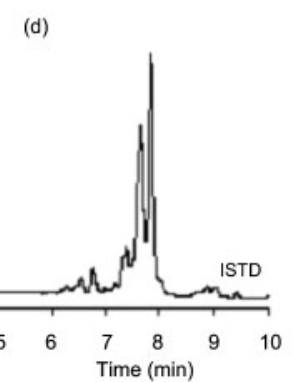

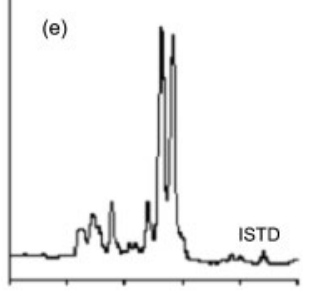

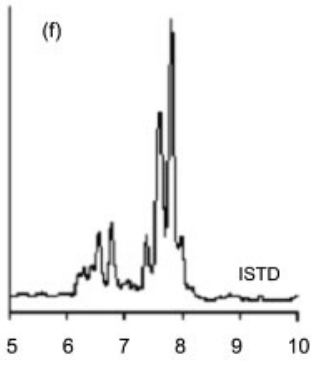

Fig. 1. Mycolic acid profiles determined by HPLC for strains LTA-388 ${ }^{\top}$ and 2003-1106 and four other RGM species. Strains: LTA-388 ${ }^{\top}$ (a); 2003-11-06 (b); M. smegmatis ATCC $19420^{\top}$ (c); M. mageritense ATCC $700351^{\top}$ (d); M. wolinskyi ATCC $700010^{\top}$ (e); M. goodii ATCC $700504^{\top}$ (f). ISTD, Internal high-molecular-mass standard. 


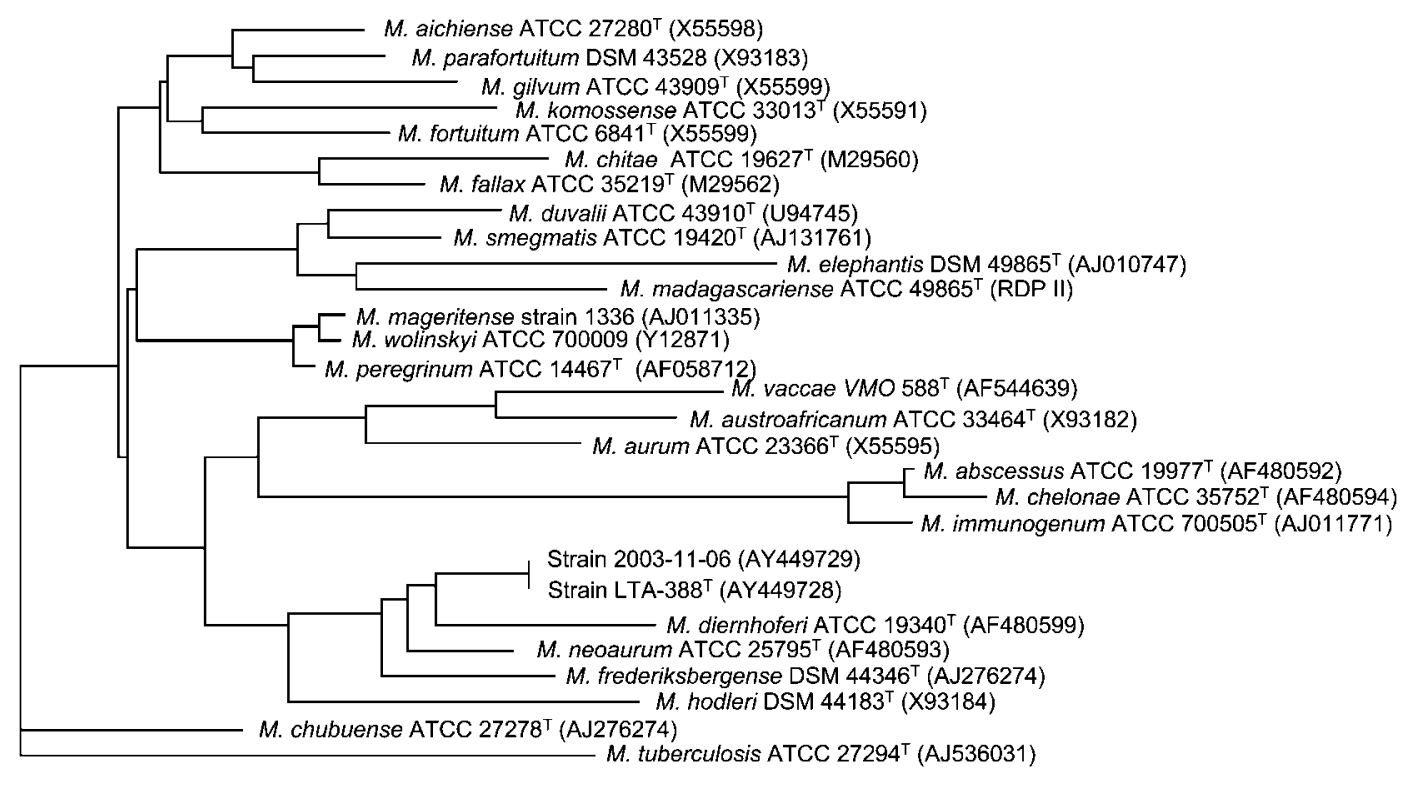

0.01

Fig. 2. Dendrogram, based on 1217 unambiguous nucleotides of the $16 \mathrm{~S}$ rRNA gene, showing the phylogenetic relationships of strains $\mathrm{LTA}^{-388^{\top}}$ and 2003-11-06 and 26 other Mycobacterium species. Similarity comparisons, multiple sequence alignments and phylogenetic analyses of 16S rRNA gene sequences with pre-compiled aligned 16S rRNA gene sequence data at RDP-II (Cole et al., 2003). The dendrogram was rooted in the sequence for M. tuberculosis as an outlier. GenBank accession numbers are shown in parentheses. The scale bar represents 1 substitution per 100 nucleotide residues.

the sequence was unique and was most similar to sequences from M. neoaurum and M. diernhoferi (95\%).

A phylogenetic comparison of $16 \mathrm{~S}$ rRNA gene sequences using 1217 aligned nucleotides is shown in Fig. 2. The sequence of the helix-18 region of the 16S rRNA gene of the study strains matched that of other RGM sequences. Four species shared a common group on the 16S rRNA gene dendrogram, the study strains being separate from the remaining 22 species evaluated (Fig. 2). We therefore compared hsp65 PRA patterns for these four species $(M$. hodleri, $M$. frederiksbergense, $M$. neoaurum and $M$. diernhoferi) with strain LTA $-388^{\mathrm{T}}$, but no similarities in restriction patterns using either BstEII or HaeIII were observed (Fig. 3).

The genotypic and phenotypic characteristics of the four isolates in this study distinguish these organisms from other Mycobacterium species. Although the two strains of this species were obtained from different continents, all four isolates were associated with either a cosmetic environment (nail salon) or an infection of a patient undergoing mesotherapy for a cosmetic purpose. Infections caused by RGM species acquired from aqueous baths at cosmetic salons are well documented (Gira et al., 2004; Sniezek et al., 2003; Murillo et al., 2000; Winthrop et al., 2002), and identification of these organisms is warranted.

The inability of the strains we studied to grow at $45^{\circ} \mathrm{C}$ or upon media containing $5 \%(\mathrm{w} / \mathrm{v}) \mathrm{NaCl}$ are traits that may be useful for distinguishing them from species belonging to the $M$. smegmatis complex, which are positive for these tests. Six additional physiological properties that can be used to distinguish strain LTA- $388^{\mathrm{T}}$ from those species found to share the greatest $16 \mathrm{~S}$ rRNA similarities are shown in Table 2. Strain LTA- $388^{\mathrm{T}}$ differs from (i) $M$. frederiksbergense, which does not grow on MacConkey agar

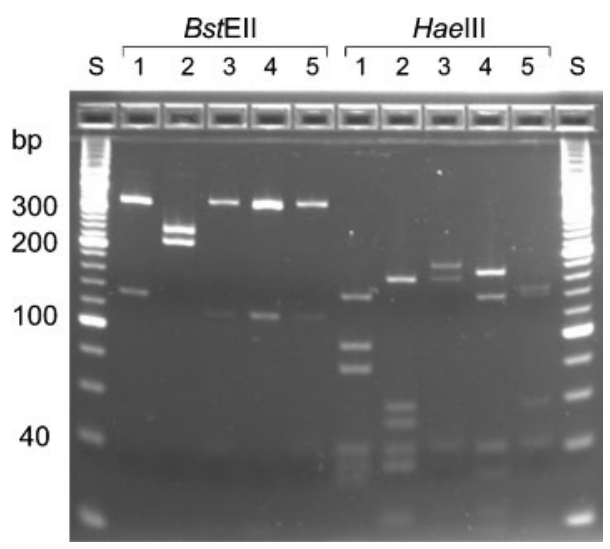

Fig. 3. hsp65 PRA patterns obtained using BstEll and Haelll. Lanes: 1, strain LTA-388'; 2, M. hodleri DSM 44183'; 3, M. frederiksbergense NRRL B-24126; 4, M. neoaurum ATCC 25796; 5, M. diernhoferi ATCC $19340^{\top}$. S, 20 and $100 \mathrm{bp}$ size standards. 
Table 2. Physiological properties useful for differentiating strain LTA-388 ${ }^{\top}$ from closely related species

Strains/species: 1, LTA-388 ${ }^{\mathrm{T}} ; 2, \quad$. frederiksbergense; 3, M. neoaurum; 4, M. hodleri; 5, M. diernhoferi. Data for reference species were taken from Tsukamura et al. (1983) and Willumsen et al. (2001). Symbols:,$+>85 \%$ of strains tested gave positive results;,$-<15 \%$ of strains gave positive results.

\begin{tabular}{|lccccc|}
\hline Characteristic & $\mathbf{1}$ & $\mathbf{2}$ & $\mathbf{3}$ & $\mathbf{4}$ & $\mathbf{5}$ \\
\hline Scotochromogenic & + & + & + & + & - \\
3-day arylsulfatase & - & - & + & - & - \\
Growth on MacConkey agar & + & - & + & - & + \\
$\quad$ (no crystal violet) & & & & & \\
Utilization of: & & & & & \\
$\quad \begin{array}{l}\text { Trehalose } \\
\text { Sorbitol }\end{array}$ & + & + & + & - & - \\
$\quad$ Citrate & - & - & - & + & - \\
& + & - & - & - & - \\
\hline
\end{tabular}

containing no crystal violet or on citrate as a sole carbon source, from (ii) M. neoaurum, which is positive for 3-day arylsulfatase production and negative for citrate utilization, from (iii) M. hodleri, which does not grow on MacConkey agar containing no crystal violet, or on citrate or trehalose, but which does grow on sorbitol, as a sole carbon source, and from (iv) $M$. diernhoferi, which is nonscotochromogenic and does not grow on trehalose, sorbitol or citrate as a sole carbon source. Although the isolates had mycolic acid patterns that most closely resembled those of members of the M. smegmatis group, DNA sequence analysis of three taxonomically useful genes showed dissimilarities with respect to these or other recognized Mycobacterium species. The occurrence of unrelated strains that develop similar mycolic acid patterns has been described (Tortoli et al., 2001). Moreover, the results for HPLC and genetic analysis are not always congruent, and the similarity, or lack of similarity, of HPLC patterns does not reflect phylogenetic relatedness of strains. The standard hsp65 PRA method (Telenti et al., 1993) showed restriction patterns (using BstEII and HaeIII) for the study strains that were easily distinguished from those of other RGM species.

We conclude, therefore, that strains LTA- $388^{\mathrm{T}}$ and 200311-06 represent two strains of a novel, and possibly pathogenic, member of the genus Mycobacterium that has characteristics that are clearly distinguishable from those of other species in this genus. We propose that this organism be named Mycobacterium cosmeticum sp. nov.

\section{Description of Mycobacterium cosmeticum sp. nov.}

Mycobacterium cosmeticum (cos.me'ti.cum. N.L. neut. adj. cosmeticum referring to cosmetics).

Cells are acid-fast rods (approx. $0.55 \times 1.5 \mu \mathrm{m}$ ) that rarely form cell aggregates in liquid culture. Motility-related structures, spores and cell branching are not present.
Colonies on Middlebrook 7H10 or LJ agar have smooth surfaces and edges, are domed and are scotochromogenic. Colonies from a dilute inoculum on $\mathrm{LJ}$ agar are visible after 3 days incubation in an aerobic atmosphere at 28 or $35^{\circ} \mathrm{C}$, but no growth is observed at $45^{\circ} \mathrm{C}$. Growth occurs on MacConkey agar without crystal violet but not on LJ agar containing $5 \%(\mathrm{w} / \mathrm{v}) \mathrm{NaCl}$. Tests for niacin production and 3-day arylsulfatase activity are negative, but tests for 14-day arylsulfatase activity, nitrate reduction and iron uptake are positive. Tests for utilization of D-mannitol, D-xylose, iso-myo-inositol, L-arabinose, D-trehalose and citrate are positive, but that for D-sorbitol utilization is negative. Isolates are susceptible in vitro to ciprofloxacin, amikacin, tobramycin, cefoxitin, clarithromycin, doxycycline, sulfamethoxazole and imipenem. The mycolic acid HPLC pattern consists of two three-peak clusters and is most similar to patterns for M. smegmatis, M. wolinskyi and M. goodii. Partial sequences of the $r p o B$ (321 bp), 16S rRNA (1506 bp) and $h s p 65(441 \mathrm{bp})$ genes are different from those of all currently recognized Mycobacterium species. Characteristics that distinguish this species from other RGM species include the inability to grow at $45^{\circ} \mathrm{C}$ or on media containing $5 \%(\mathrm{w} / \mathrm{v}) \mathrm{NaCl}$, the utilization of trehalose or citrate, but not sorbitol, as a sole carbon source, and a unique banding pattern after restriction of a $441 \mathrm{bp}$ region of the $h s p 65$ gene that includes major fragments of 310 and $130 \mathrm{bp}$ (when BstEII is used) or of 140 , 96, 80 and $40 \mathrm{bp}$ (when HaeIII is used).

The type strain, isolate LTA $-388^{\mathrm{T}}\left(=\right.$ ATCC BAA $-878^{\mathrm{T}}=$ CIP $108170^{\mathrm{T}}$ ), was isolated from a granulomatous lesion of a female patient in Venezuela who was undergoing mesotherapy.

\section{Acknowledgements}

We are grateful to Hans G. Trüper for specific expert assistance with the scientific epithet.

\section{References}

Bloom, J. M. (1885). The bacillus of syphilis. Lancet i, 609-610.

Butler, W. R. \& Guthertz, L. S. (2001). Mycolic acid analysis by high-performance liquid chromatography for identification of Mycobacterium species. Clin Microbiol Rev 14, 704-726.

Butler, W. R., Floyd, M. M., Silcox, V. \& 9 other authors (1996). Standardized Method for HPLC Identification of Mycolic Acids of Mycobacteria. Atlanta, GA: Centers for Disease Control and Prevention.

Cole, J. R., Chai, B., Marsh, T. L. \& 8 other authors (2003). The Ribosomal Database Project (RDP-II): previewing a new autoaligner that allows regular updates and the new prokaryotic taxonomy. Nucleic Acids Res 31, 442-443.

Cooksey, R. C., Limor, J., Morlock, G. P. \& Crawford, J. T. (2003). Identifying Mycobacterium species and strain typing using a microfluidic labchip instrument. Biotechniques 35, 786-794.

Edwards, U., Rogall, T., Ende, M. \& Bottger, E. C. (1989). Isolation and direct sequencing of entire genes. Characterization of a gene coding for 16 S ribosomal RNA. Nucleic Acids Res 17, 7843-7853. 
Falkingham, J. O., III (1996). Epidemiology of infection by non tuberculous mycobacteria. Clin Microbiol Rev 9, 177-215.

Felsenstein, J. (1989). PHYLIP - phylogeny inference package (version 3.2). Cladistics 5, 164-166.

Floyd, M., Guthertz, L. S., Silcox, V. A., Duffey, P. S., Jang, Y., Desmond, E. P., Crawford, J. T. \& Butler, W. R. (1996). Characterization of an SAV organism and proposal of Mycobacterium triplex sp. nov. J Clin Microbiol 34, 2963-2967.

Gira, A. K., Reisenauer, A. H., Hammock, L. \& 10 other authors (2004). Mycobacterium mageritense furunculosis associated with footbaths at a nail salon. J Clin Microbiol 42, 1813-1817.

Harmsen, D., Rothganger, J., Singer, C., Albert, J. \& Frosch, M. (1999). Intuitive hypertext-based molecular identification of microorganisms. Lancet 353, 291.

Hector, J. S., Pang, Y., Mazurek, G. H., Zhang, Y., Brown, B. A. \& Wallace, R. J., Jr (1992). Large restriction patterns of genomic Mycobacterium fortuitum DNA as strain-specific markers and their use in epidemiologic investigation of four nosocomial outbreaks. J Clin Microbiol 30, 1250-1255.

Hernandez, S. M., Morlock, G. P., Butler, W. R., Crawford, J. T. \& Cooksey, R. C. (1999). Identification of Mycobacterium species by PCR-restriction fragment length polymorphism analyses using fluorescence capillary electrophoresis. J Clin Microbiol 37, 3688-3692.

Jukes, T. H. \& Cantor, C. R. (1969). Evolution of protein molecules. In Mammalian Protein Metabolism, vol. 3, pp. 21-132. Edited by H. N. Munro. New York: Academic Press.

Kent, P. T. \& Kubica, G. P. (1985). Public Health Mycobacteriology: a Guide for the Level III Laboratory. US Department of Health and Human Services Publication no. (CDC) 86-8230. Atlanta, GA: Centers for Disease Control and Prevention.

Lee, H., Bang, H.-E., Bai, G.-H. \& Cho, S.-N. (2003). Novel polymorphic region of the $r p o B$ gene containing Mycobacterium speciesspecific sequences and its use in identification of mycobacteria. J Clin Microbiol 41, 2213-2218.

Linton, C. J., Jalal, H., Leeming, J. P. \& Miller, M. R. (1994). Rapid discrimination of Mycobacterium tuberculosis strains by random amplified polymorphic DNA analysis. J Clin Microbiol 32, 2169-2174.
Murillo, J., Torres, J., Bofill, L. \& 8 other authors (2000). Skin and wound infection by rapidly growing mycobacteria. Arch Dermatol 136, 1347-1352.

NCCLS (2002). Susceptibility testing of mycobacteria, nocardia, and other aerobic actinomycetes. Approved standard M24-A. Wayne, PA: National Committee for Clinical Laboratory Standards.

Romling, U. \& Tummler, B. (2000). Achieving $100 \%$ typeability of Pseudomonas aeruginosa by pulsed-field electrophoresis. J Clin Microbiol 38, 464-465.

Saitou, N. \& Nei, M. (1987). The neighbor-joining method: a new method for reconstructing phylogenetic trees. Mol Biol Evol 4, 323-330.

Shinnick, T. M. (1987). The 65-kilodalton antigen of Mycobacterium tuberculosis. J Bacteriol 169, 1080-1088.

Sniezek, P. J., Graham, B. S., Busch, H. B. \& 8 other authors (2003). Rapidly growing mycobacterial infections after pedicures. Arch Dermatol 139, 629-634.

Telenti, A., Marchesi, F., Balz, M., Bally, F., Bottger, E. C. \& Bodmer, T. (1993). Rapid identification of mycobacteria to the species level by polymerase chain reaction and restriction enzyme analysis. J Clin Microbiol 31, 175-178.

Tortoli, E., Vartoloni, A., Bottger, E. C. \& 8 other authors (2001). Burden of unidentifiable mycobacteria in a reference laboratory. J Clin Microbiol 39, 4058-4065.

Tsukamura, M., Van der Meulen, H. J. \& Grabow, W. O. K. (1983). Numerical taxonomy of rapidly growing, scotochromogenic mycobacteria of the Mycobacterium parafortuitum complex: Mycobacterium austroafricanum sp. nov., nom. rev. Int J Syst Bacteriol 33, 460-469.

Willumsen, P., Karlson, U., Stackebrandt, E. \& Kroppenstedt, R. M. (2001). Mycobacterium frederiksbergense sp. nov., a novel polycyclic aromatic hydrocarbon-degrading Mycobacterium species. Int J Syst Evol Microbiol 51, 1715-1722.

Winthrop, K. L., Abrams, M., Yakrus, M., Schwarz, I., Ely, J. \& Gillies, D. (2002). An outbreak of mycobacterial furunculosis associated with footbaths at a nail salon. $N$ Engl $J$ Med 346, 1366-1371. 